\title{
ISOLATED DRAINAGE OF THE INFERIOR VENA CAVA TO THE LEFT ATRIUM
}

BY

\author{
A. W. VENABLES
}

\section{From Royal Children's Hospital, Melbourne, Australia}

Isolated drainage of either the superior or inferior vena cava to the left atrium is a rare condition. Isolated drainage of the inferior vena cava to the left atrium has been described only by Gardner and Cole (1955) and by Meadows, Bergstrand, and Sharp (1961). The condition leads to a right-toleft shunt in the absence of clinical features of cardiovascular abnormalities.

A further case in which the diagnosis was confirmed by cardiac catheterization is here put on record. Angiography demonstrated an important alternative venous pathway carrying lower extremity blood to the superior vena cava by the azygos vein. The patient sustained an unfortunate but unusual neurological complication of the investigation and this also is reported.

\section{Case Report}

Carol M. was seen at the age of 9 years with a history that since early childhood she had suffered from shortness of breath which prevented her from indulging in normal play activities. Her parents had not noted any cyanosis except when she was cold after swimming. She was a thin girl weighing $24.4 \mathrm{~kg}$. Her lips were slightly dusky at rest and her fingers and toes were moderately clubbed. Observation during a test exercise showed that she became obviously cyanosed and somewhat dyspnoic.

The saturation obtained by ear oximetry at rest was 95 per cent. This fell to 84 per cent with moderate exertion, confirming the clinical observations. Her hæmoglobin level was $14.0 \mathrm{~g}$. per $100 \mathrm{ml}$. and the red cell count was $5.9 \times 10^{6}$ per c.mm.

Findings on clinical examination were otherwise completely normal. There were no murmurs in the heart or over the lung fields. Chest radiogram showed a heart of normal contour and size, with no evidence of any abnormal arterio-venous communications in the lung. There was no left superior vena caval shadow (Fig. 1). The electrocardiogram was normal.

Cardiac catheterization was performed in August 1961. A catheter passed into the inferior vena cava from the right long saphenous vein in the groin entered the left atrium directly. From there it entered the pulmonary veins and the left ventricle. The hepatic veins were entered from the inferior vena cava at the normal level. A second catheter, passed from the right median cubital vein, entered the right atrium and thence the right ventricle and pulmonary arteries; but would not pass inferiorly from the right atrium either to the inferior vena cava or to the hepatic veins. Fig. 2 shows the two catheters in the respective atria in the left anterior oblique view. The saturation and pressures in the various chambers are given in the Table.

At this point the inferior vena caval catheter was replaced with a side opening angiographic catheter. The child was anæsthetized uneventfully with intravenous thiopentone and succinyl choline and a selective angiogram was performed by injection of $18 \mathrm{ml}$. of 60 per cent urografin apparently into the inferior vena cava low in the abdomen. All the dye, however, entered the heart via the azygos vein and superior vena cava. The right atrium, right ventricle, and pulmonary vasculature were outlined. The azygos vein appeared quite large. It was thought that the catheter was simply lying below the junction of the azygos system with the inferior vena cava and that the findings represented diversion of the blood stream from the inferior vena cava at that site. It was therefore advanced to a position just below the diaphragm and a further injection performed. Similar findings on the television screen showed that the catheter had in fact been advanced up the azygos system and not up the inferior vena cava. The catheter was then withdrawn almost completely and passed easily up the inferior vena cava to the left atrium. No further injections of dye were made.

After operation the child appeared slow to wake. Some seven hours after the procedure it was clear 


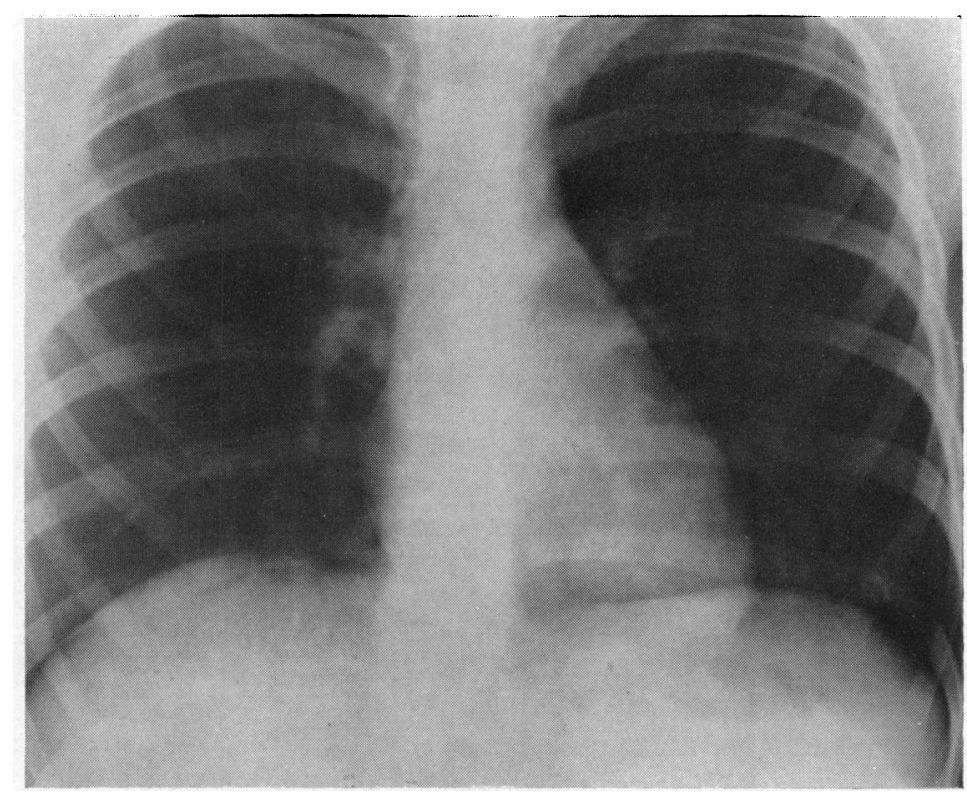

FIG. 1.-Chest radiogram of patient with isolated drainage of inferior vena cava into left atrium.

that she was unconscious although restless and stirring in response to painful stimuli. Examination revealed ophthalmoplegia which was complete in the left eye with dilatation of that pupil, but was associated with some lateral flickering of the right eye. Muscle tone fluctuated with general increase in tendon reflexes. Both plantars appeared to be extensor. The optic discs were normal. The pressure recorded at lumbar puncture was $60 \mathrm{~mm}$. of cerebrospinal fluid.

Hypothermia was maintained with chlorpromazine and external cooling for 48 hours. On rewarming to a normal temperature the child developed deviation of her head and eyes to the right, but otherwise her neurological findings remained unchanged. Tracheotomy was necessary to permit control of tracheobronchial exudate.

Three weeks after catheterization she had become conscious and was able to obey some commands and to co-operate in spoon feeding. There was considerable muscle weakness but the limb tone was fairly normal apart from the left arm in which it was reduced. Subsequently her condition progressively improved. Ten

\section{TABLE}

Data of Simultaneous Catheterization of Right Heart via Superior Vena Cava and of Left Heart via INFERIOR VENA CAVA

\begin{tabular}{|c|c|c|c|c|}
\hline & & & $\begin{array}{l}\text { Percentage } \\
\text { oxygen } \\
\text { saturation }\end{array}$ & $\begin{array}{c}\text { Pressure } \\
(\mathrm{mm} . \mathrm{Hg}) \\
\text { S/D }\end{array}$ \\
\hline $\begin{array}{l}\text { Superior vena cava } \\
\text { Right atrium . } \\
\text { Right ventricle } \\
\text { Pulmonary artery } \\
\text { Inferior vena cava } \\
\text { Left atrium . . } \\
\text { Left ventricle . } \\
\text { Pulmonary vein }\end{array}$ & $\begin{array}{l}\ldots \\
\ldots \\
\ldots \\
\cdots \\
\cdots \\
\ldots\end{array}$ & $\begin{array}{l}\cdots \\
\cdots \\
\cdots \\
\cdots \\
\cdots \\
\cdots\end{array}$ & $\begin{array}{l}69 \\
70 \\
70 \\
69 \\
78 \\
93 \\
93 \\
98\end{array}$ & $\begin{array}{l}\bar{Z} \\
14 / 0 \\
11 / 5 \\
\overline{85 / 0}\end{array}$ \\
\hline
\end{tabular}




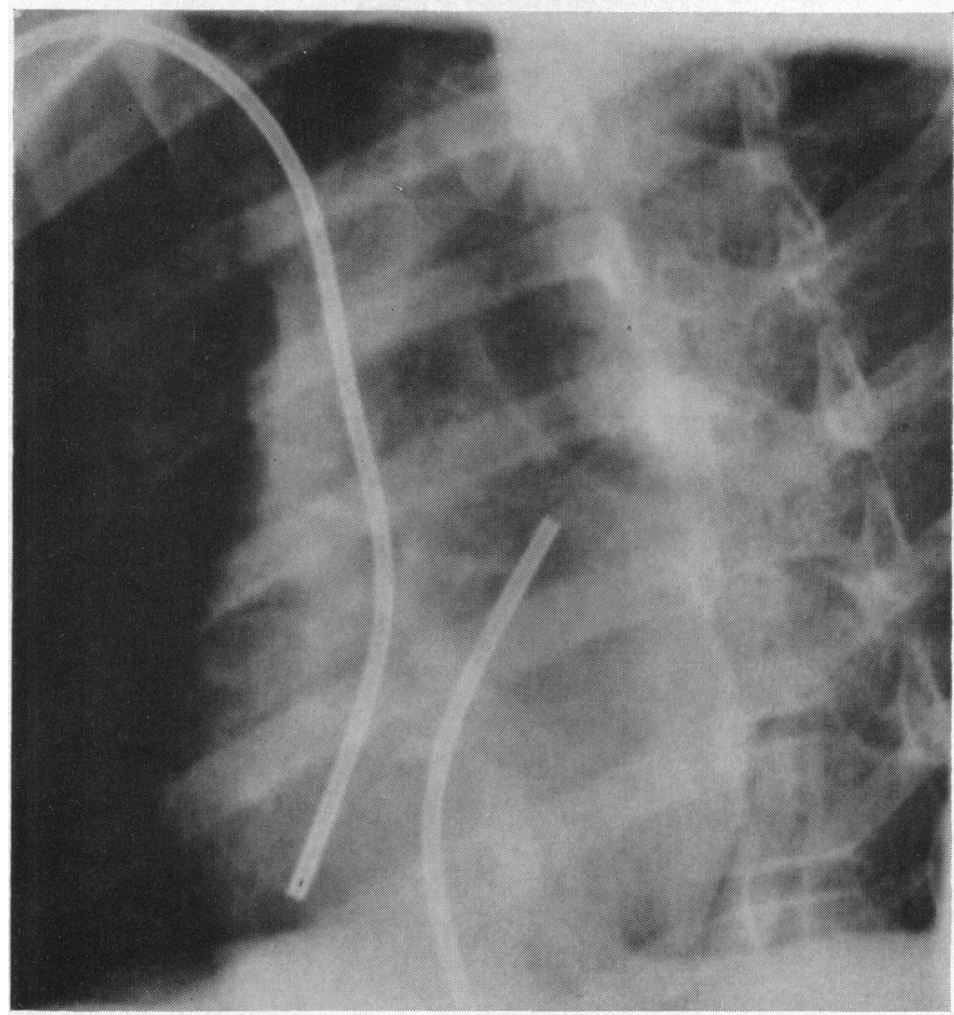

FIG. 2.-Left anterior oblique projection showing catheters entering right and left atria from superior and inferior venæ cavæ respectively.

months after catheterization she had a severe left hemiplegia with considerable speech difficulty. She was emotionally rather labile but appeared to have normal intellectual function and had been accepted at a school for handicapped children.

\section{Discussion}

The findings in this patient are typical of drainage of a vena cava into the left atrium. They permitted accurate clinical diagnosis which was confirmed as described. The course has been complicated by the neurological catastrophe that occurred at the time of cardiac catheterization-a complication that appears most likely to have been due to embolism. Its relation to other complications of investigation has been discussed elsewhere (Case 20, Venables and Hiller, 1963).

From the cardiovascular aspect the prognosis appears good. The patient of Gardner and Cole (1955) died at 32 years from factors other than the vena cava anomaly. The present patient appeared to have sufficient disability before investigation to warrant relief of symptoms if that were possible. With the reduction in activity resulting from the hemiplegia operation is not now indicated.

Angiography demonstrated a significant alternative pathway for inferior vena caval flow to the right atrium via the azygos system. The necropsy finding of a dilated azygos vein in the patient of Gardner and Cole suggests a similar situation. The more blood conveyed by the azygos system the less important becomes the right-to-left shunt via the inferior vena cava. In this patient the shunt became more substantial with exertion. The presence of substantial azygos drainage could well 
be relevant to surgical considerations regarding diversion of the inferior vena caval flow to the right atrium, if this were to be attempted.

\section{Summary}

A further case is reported of isolated drainage of the inferior vena cava to the left atrium.

The presence of significant alternative venous drainage from the lower extremities to the right atrium via the azygos system is noted.

An unusual cerebral complication of cardiac catheterization and angiography is described.

References

Gardner, D. L., and Cole, L. (1955). Long survival with inferior vena cava draining into left atrium. Brit. Heart J., 17, 93 .

Meadows, W. R., Bergstrand, I., and Sharp, J. T. (1961). Isolated anomalous connection of a great vein to the left atrium: The syndrome of cyanosis and clubbing, "normal" heart, and left ventricular hypertrophy on electrocardiogram. Circulation, 24, 669.

Venables, A. W., and Hiller, H. G. (1963). Complications of cardiac investigation. Brit: Heart J., 25, 334 